\title{
COVID-19 PANDEMIC: AN INHIBITOR OF UNIVERSAL HEALTH COVERAGE PROGRAMME: A VIEWPOINT
}

\author{
Helen Idubamo Wankasi (PhD) \\ Department of Community Health Nursing, Faculty of Nursing Sciences, Niger Delta \\ University, Wilberforce Island, Nigeria \\ Orcid.org 0000-0002-8403-5555 \\ Email: hidubamo@gmail.com
}

Cite this article:

Helen Idubamo Wankasi (2021), COVID-19 Pandemic: An Inhibitor of Universal Health Coverage Programme: A ViewPoint. African Journal of Health, Nursing and Midwifery 4(5), 1-13. DOI: 10.52589/AJHNMP2AX15UL.

\section{Manuscript History}

Received: 12 June 2021

Accepted: 9 July 2021

Published: 26 July 2021

Copyright $\odot 2020$ The Author(s). This is an Open Access article distributed under the terms of Creative Commons AttributionNonCommercial-NoDerivatives 4.0 International (CC BY-NC-ND 4.0), which permits anyone to share, use, reproduce and redistribute in any medium, provided the original author and source are credited.
ABSTRACT: Ever since the re-emergence of Covid-19 as a pandemic, healthcare facilities (human and materials) have been overstressed, evidenced by the rate at which frontline healthcare workers fall sick and die in the course. In some healthcare institutions, the narrative has changed with regards to the number of days to access physicians for treatment, but selected and booked only on specific days and periods, except in extreme emergencies are able to access physicians un-booked. This is inconsistent with the intent of Universal Health Coverage and the Sustainable Development Goals. This paper, therefore, highlighted the objectives, covering a brief overview of COVID19 and Universal Health Coverage; identified countries developed (Germany 1883) and emerging (South Africa/Nigeria) that have adopted Universal Health Coverage as well described how COVID-19 stands as an inhibitor to the achievement of Universal Health Coverage. At the tail end, recommendations are made on the way forward on the need for effective governance, manpower sourcing and general strengthening of the healthcare system.

KEYWORDS: COVID-19 Pandemic, Universal Health, Healthcare Facilities 


\section{INTRODUCTION}

The World Health Organization (WHO), 2020) affirmed a survey`s report that since the reemergence of Coronavirus disease and was declared a full-blown pandemic in 2019, healthcare services have been severely disrupted and stressed. The survey report, which was completed by one hundred and fifty-five (155) countries during a 3-week period in May 2020 confirmed that the impact of the disruption is global, however, the worst heat is on low and middle-income countries, in terms of financial hardship. Earlier on, WHO (2019) had iterated that, Universal Health Coverage (UHC) requires all persons to receive needed quality health services without suffering financial hardship in the course of health promotion, prevention, treatment and rehabilitation as well as palliative care. This reiteration is a mismatch and inconsistent with the global happenings. The purpose of this viewpoint paper is to highlight how COVID-19 stands as a huge inhibitor towards the achievement of Universal Health Coverage in Nigeria.

\section{Goal and objectives of this discussion}

The overall goal of this paper is to further sensitize, educate and share knowledge with readers of the devastating effect of Covid-19, on the Universal Health Coverage programme.

The specific objectives of this viewpoint are to:

provide a brief overview of COVID-19, covering structural description, origin, pandemic, signs and symptoms.

highlight the overview of Universal Health Coverage (definition; emergence of UHC; identify few countries that have adopted UHC; nature of UHC, mode of payment and benefits

describe how COVID-19 stands as an inhibitor to the achievement of UHC.

make recommendations on the way forward to improve UHC

\section{Brief overview and background of COVID-19}

Corona is a minute spherical size (range between $50 \mathrm{~nm}$ to $140 \mathrm{~nm}$ ) in diameter; single-stranded RNA; weighs 26 - 32kbs; in length varies from 9 to $12 \mathrm{~nm}$ virus (Cuffari \& Coveney 2021) that derived its name from the crown-like nature, as seen (Figures $1 \mathrm{a} \& \mathrm{~b}$ ). (Shereena, Khana, Kazmic, Bashira \& Siddiquea, 2020). Panchalingala, 2020). According to Cuffari and Coveney (2021), the size of any viral or bacterial particle can provide a useful insight into how these infecting species can wreak havoc on host cells. This could be inferred that; the tiny nature of the virus amplified its widespread. Shereena et al. (2020) assert that the virus is subclassed into alpha (a), beta (b), gamma (c) and delta (d) coronavirus. Below are two diagrams of deadly severe acute respiratory syndrome coronavirus. 


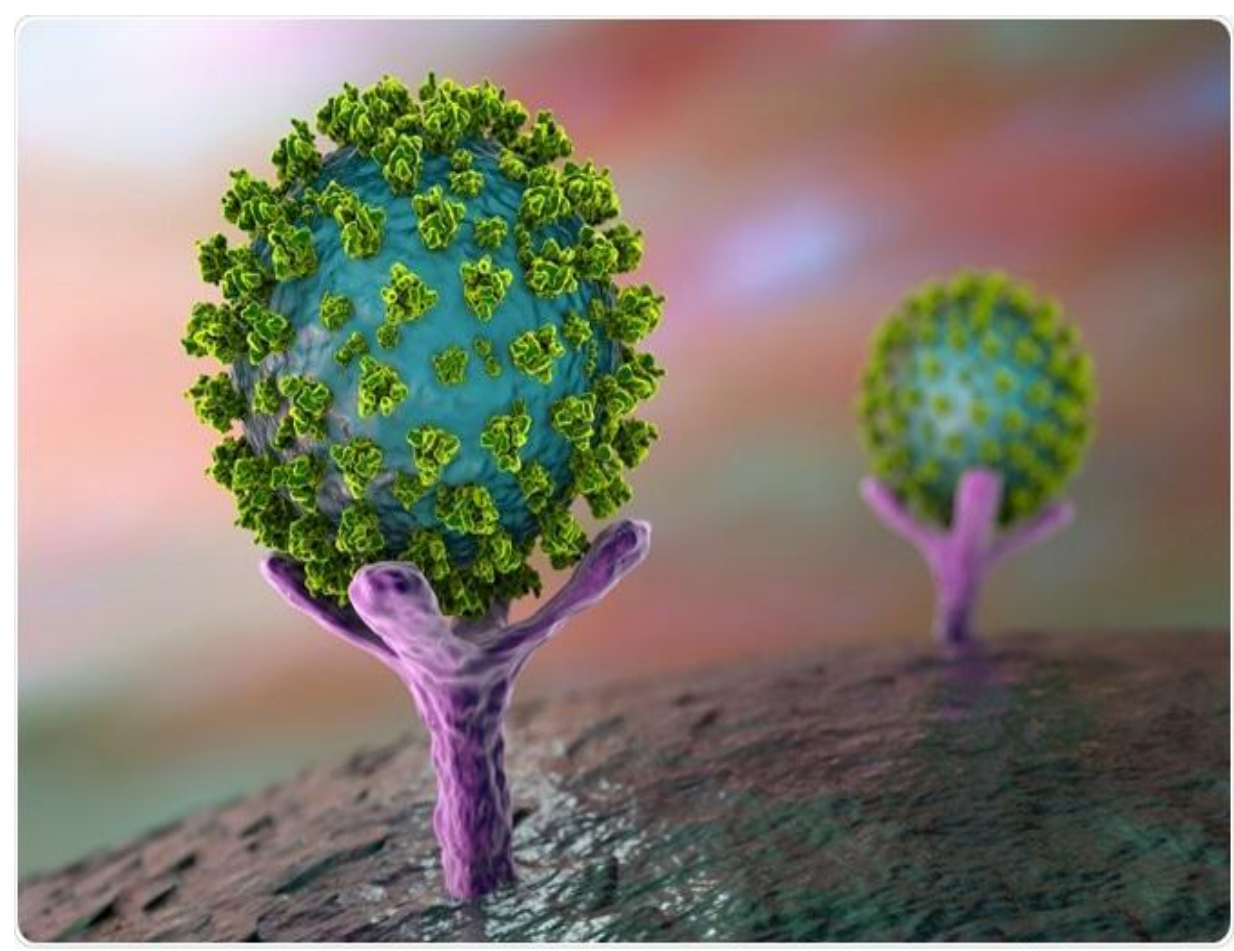

Figure 1a: Coronavirus. An excerpt from Kateryna Kon/Shutterstock.com

Severe acute respiratory syndrome coronavirus 2 (SARS-CoV-2)

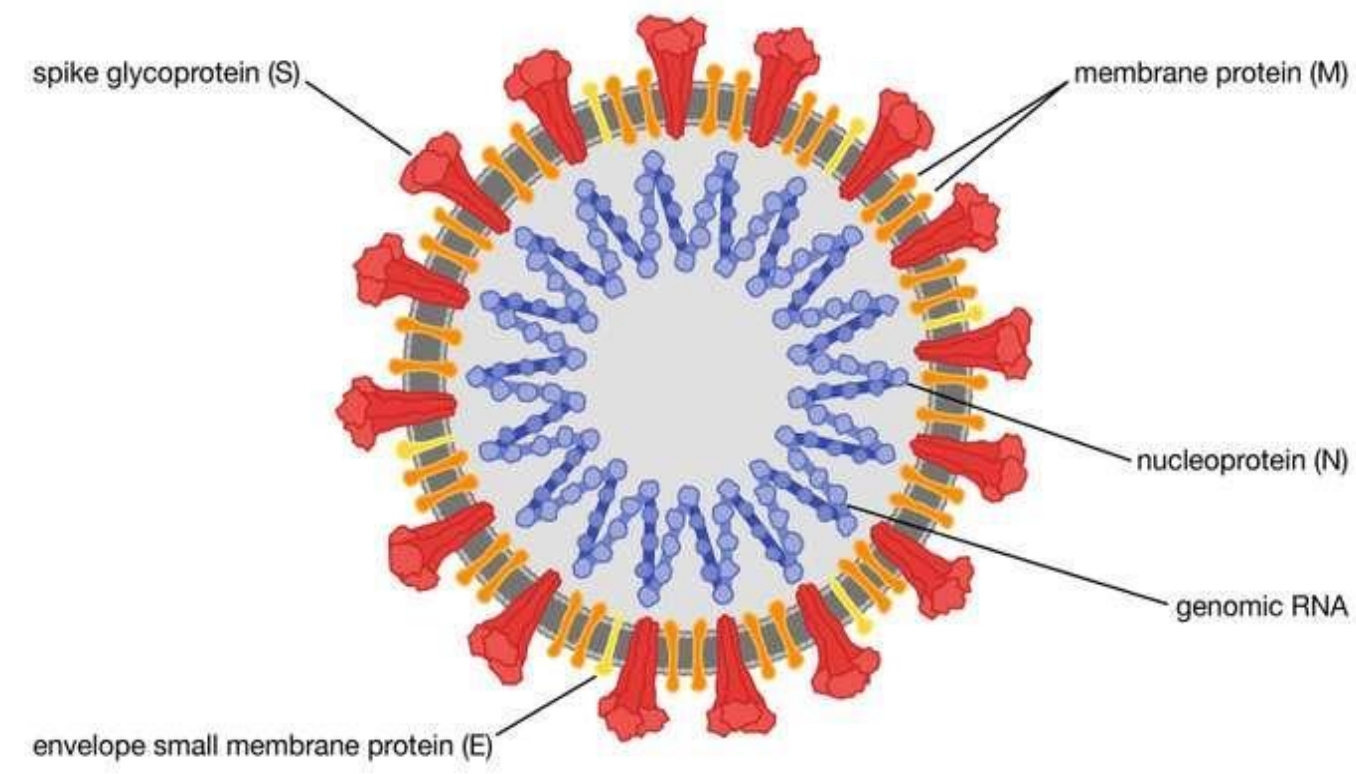

C) Encyclopædia Britannica, Inc.

Figures 1b: The SARS-CoV-2, (Coronavirus) an excerpt from Encyclopedia Britannica, Inc./Patrick O'Neill Riley. 


\section{Origin of Coronavirus}

The origin of when and how this seemingly new virus came into existence is unclear, however, there are speculations that the virus was named as Wuhan coronavirus or 2019 novel coronavirus (2019-nCov) by Chinese researchers. COVID-19 illustrates the virus and the year the virus drew the world`s attention (World Health Organisation`s (WHO) COVID-19 response, 2020).

As earlier stated, the virus was reported to be a member of the b group of coronaviruses, meaning, it has the potential characteristic of presenting itself as either: severe acute respiratory syndrome coronavirus (SARS-CoV), H5N1 influenza A, H1N1 2009 or Middle East respiratory syndrome coronavirus (MERS-CoV). In whichever form it presents, the virus affects the human lungs and causes acute respiratory distress syndrome (ARDS) which leads to ultimately fatality (Shereena et al. 2020).

\section{Zoonotic source of transmission}

In 2002, proponents thought the virus infect only animals until the world witnessed the SARS outbreak caused by SARS-CoV in Guangdong, but erupted in Wuhan all in China from recent reports (Riou \& Althaus 2020; Peiris, Guan \&Yuen 2004; Pyrc, Berkhout \& Van Der Hoek 2007). Ever since, more recent studies have proved that the virus had already killed more than eighteen hundred and infected over seventy thousand individuals within the first fifty days of the epidemic (Sowole, Ibrahim, Sangare, \& Johnson, 2020). Guo, et al (2020) state that, before the outbreak of COVID-19 for the world to take action, it has already swept across China rapidly and has spread to 85 countries/territories/areas outside of China as of $5^{\text {th }}$ March 2020. In other words, ever since its emergence, there has been an unprecedented spread of the diseases from a global perspective (Sowole et al 2020).

Besides, a similar school of thought from the WHO official page indicates that the virus which causes COVID-19 most probably has its ecological reservoir in bats, and transmission of the virus to humans has likely occurred through an intermediate animal host, which could be a domestic animal, a wild animal or a domesticated wild animal which has not yet been identified. While the zoonotic source of the virus is currently unknown, the following general recommendations for reducing the risk of transmission of zoonotic pathogens in live animal markets are done. In a bid to contain the rapid spread, WHO in early January 2020 circulated an all-inclusive compendium of regulatory documents for countries to adopt, covering topics related to the management of an outbreak of a novel disease:

- Infection prevention and control

- Laboratory testing and

- Building capacities of all stakeholders and the public at all levels.

Later in the same month, the WHO, Director-General raised alarm and declared the coronavirus outbreak a public health emergency of international concern (PHEIC), because, the disease was almost becoming beyond human containment. Consequently, WHO made the following sixteen (16) recommendations to safeguard human beings: 
1. first, WHO (2020) recommends that anyone visiting live animal markets, wet markets, or animal product markets should practice general hygiene measures, such as:

2. regular handwashing with soap and water after touching animals and animal products $\backslash$

3. avoid touching eyes, nose, or mouth with hands.

4. avoid contact with sick animals or spoiled animal products.

5. any contact with other animals possibly living in the market (e.g. stray cats and dogs, rodents, birds, bats) should be avoided.

6. attention should also be taken to avoid contact with potentially contaminated animal waste or fluids on the soil or structures of shops and market facilities.

7. avoid the consumption of raw or undercooked animal/products.

8. raw meat, milk, or animal organs should be handled with care, to avoid crosscontamination with uncooked foods, as per good food safety practices.

9. WHO (2020) also warned that slaughterhouse workers, veterinarians in charge of animal and food inspection in markets, market workers, and those handling live animals and animal products should practice strict and good personal hygiene, such as frequent hand washing.

10. workers should wear protective gowns and gloves while professionally handling animals and fresh animal products.

11. equipment and working stations should be disinfected frequently, at least once a day.

12. protective clothing should be removed after work and washed daily.

13. workers should avoid exposing family members to soiled work clothing, shoes, or other items. It was therefore recommended that protective clothes and items remain at the workplace for daily washing.

14. as a general recommendation, WHO (2020) states that sick animals should never be slaughtered for consumption

15. dead animals should be safely buried or destroyed and contact with their body fluids should be avoided without protective clothes.

16. Veterinarians should maintain a high level of vigilance and report any unusual event detected in any animal species present in the markets to veterinary authorities.

Despite these recommendations, as of February 2021, the number of cases World Health Organization (WHO) (2021) flashed in its dashboard was 104370550 confirmed cases; 2271 180 of coronavirus infection-related confirmed deaths and 223, covering countries, areas or territories with cases. The table below highlights names of some countries, cases cumulative total, cases newly infected, deaths cumulative total, deaths newly reported and transmission classification. 
Table 1: Situation by Country, Territory and Area. Source WHO.

\begin{tabular}{|c|c|c|c|c|c|}
\hline Name & $\begin{array}{l}\text { Cases } \\
\text { cumulative } \\
\text { total }\end{array}$ & $\begin{array}{l}\text { Cases } \\
\text { newly } \\
\text { reported }\end{array}$ & $\begin{array}{l}\text { Deaths } \\
\text { cumulativ } \\
\text { e total }\end{array}$ & $\begin{array}{l}\text { Deaths } \\
\text { newly } \\
\text { reporte } \\
\text { d }\end{array}$ & $\begin{array}{l}\text { Transmissi } \\
\text { on } \\
\text { Classificati } \\
\text { on }\end{array}$ \\
\hline Global & $\begin{array}{l}104,370,55 \\
0\end{array}$ & $\begin{array}{l}355,04 \\
1\end{array}$ & $\begin{array}{l}2,271,18 \\
0\end{array}$ & $\begin{array}{l}10,42 \\
2\end{array}$ & $*$ \\
\hline $\begin{array}{l}\text { STE } \\
\mathrm{UK}\end{array}$ & $3,892,463$ & 20,634 & 110,250 & 915 & $\begin{array}{l}\text { Communi } \\
\text { ty } \\
\text { Transmiss } \\
\text { ion }\end{array}$ \\
\hline Italy & $2,597,446$ & 13,656 & 90,241 & 420 & $\begin{array}{l}\text { Clusters } \\
\text { of } \\
\text { Cases }\end{array}$ \\
\hline 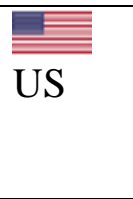 & $26,172,274$ & 0 & 443,256 & 0 & $\begin{array}{l}\text { Communi } \\
\text { ty } \\
\text { Transmiss } \\
\text { ion }\end{array}$ \\
\hline India & $10,802,591$ & 12,408 & 154,823 & 120 & $\begin{array}{l}\text { Clusters } \\
\text { of } \\
\text { Cases }\end{array}$ \\
\hline $\mathrm{RSA}$ & $1,466,767$ & 3,751 & 45,605 & 261 & $\begin{array}{l}\text { Communi } \\
\text { ty } \\
\text { Transmiss } \\
\text { ion }\end{array}$ \\
\hline
\end{tabular}

N/B: Community transmission is when there is no clear source of origin of the infection in a community. It happens when you can no longer identify who became infected after being exposed to someone who interacted with people from the other infected communities. Cluster transmission is referred to as transmission from clustered areas such as religious organisations, families, clubhouses etc (Liu · 2020).

Whereas in Nigeria, from Jan 3 to 5:00 pm CET, 5 February 2021, there have been 136,030 confirmed cases of COVID-19 with 1,632 deaths. The implications of these figures are that no region is without traces of the virus in a global perspective and that makes the virus pandemic. Again, it is a pandemic because it covers a wide geographical area and affects a large proportion of the world's population. As at last update on $11^{\text {th }}$ June 2021 , numbers at a glance in WHO Dashboard indicates, 174439 909, confirmed cases 3768 987, and vaccine doses administered 2156550767.

\section{Signs and Symptoms}

COVID-19 affects different people in different ways, most infected persons develop mild to moderate illness and recover without hospitalization. Nevertheless, the common symptoms 
exhibit by most persons is: fever, dry cough, tiredness, and the less common symptoms are: aches and pains, sore throat, diarrhoea, conjunctivitis, headache and loss of taste or smell, a rash on the skin, or discolouration of fingers or toe due to reduced oxygen circulation. Others are from mild to severe breathlessness.

\section{Universal Health Coverage}

Universal Health Coverage (UHC) is defined as a type of health care delivery system in Nigeria officially designated in response to United Nations (UN-designated- World Health Assembly in the year 2005 programme) call to strong, equitable and resilient health systems and universal health coverage that will impact all human beings. In other words, UHC is firmly based on the 1948 WHO Constitution, which declares health a fundamental human right and commits to ensuring the highest attainable level of health for all. Because of its relevance, a day $\left(12^{\text {th }}\right.$ December) annually is set aside globally to raise awareness of the need for health services.

\section{Emergence of UHC}

WHO (2019) postulates that:

- At least half of the world's population still do not have full coverage of essential health services.

- About 100 million people are still being pushed into extreme poverty (defined as living on 1.90 USD or less a day) because they have to pay for health care.

- Over 930 million people (around $12 \%$ of the world's population) spend at least $10 \%$ of their household budgets to pay for health care.

- Earlier on, hospital services were rendered free, yet were accessed by those in urban areas and only those of a certain class in the society. Whereas the rural dwellers had not such opportunities and those who attempted travelled long-distance were made to pay from their pockets, which brought unpleasant financial hardship and economic inequalities.

- Above all, all UN Member States have agreed to try to achieve universal health coverage by 2030, as part of the Sustainable Development Goals. Since the pronouncement of this lofty idea, a number of countries have adopted it though, at different times, few are stated below.

Table 2: Foreign countries that have adopted Universal Health Coverage with dates of commencement. Source: New York Department of Health 2011 update.

\section{Country}

Australia

South Korea

Spain

Sweden

Switzerland

United Arab Emirates
Start Date of

Universal Health Care

1975

1988

1986

1955

1994

1971 
United Kingdom

1948

Germany

Netherlands

New Zealand

Norway

Portugal

Singapore

Republic of South Africa-

Nigeria-------------
1966

1938

1912

1979

1993

\section{Nature of Universal Health Coverage}

The three pillars of health systems for Universal Health Coverage - are collaborative in nature, such as service delivery, health financing and governance in consonance with its aims and objectives which are: to provide health care and financial protection to all people in a given country with three related objectives:

equity in access - everyone who needs health services should get them, and not simply those who can pay for them;

quality of health services - good enough to improve the well-being of all Nigerians. It simply means that UHC is at the core of economic development.

\section{Modes of Payment}

There are four basic modes of paying for health coverage practised in Nigeria namely: out-ofpocket payment, individual private insurance, employment-based group private insurance, and government financing also known as the quad-function model (Enabulele, 2021).

\section{Benefits of UHC}

The vulnerable in the society can take advantage of the program, maintain their health and impact the immediate and distant society meaningfully which are memorable and significant to individual growth.

Another benefit of UHC is that it equalizes service, which no healthcare practitioner or institution with no doctor can render unequivocally. It means everyone gets the same level of care, which ultimately leads to a healthier workforce and longer life expectancy for all.

Followed by the adoption of the UHC by the World Health Assembly, in the 2030 Sustainable Development Goal (SDG) agenda as the eighth target of SDG 3, greater global attention is now focused on the achievement of UHC. Global attention on health affects everyone, no matter where you live. Aside from the fact that it is appropriate to do, it would also create good global health benefits for all.

While the successes recorded so far vary in different countries and continents, the case of Nigeria that is down the ladder, is not the same, judging it is still far below expectation. It means that stakeholders should redouble their effort towards achieving the stated goal. Nigeria's main strategic mechanism for achieving UHC is her National Health Insurance Scheme (NHIS), which is a contributory social health insurance scheme. Since the formal 
launch of the NHIS on June 6, 2005, not more than 4 per cent of Nigeria's population has been covered by the scheme (Enabulele, 2021). Now with the advent of COVID-19, it seems to achieve both the SDG 3 and Universal Health coverage has become an uphill task due to several factors referred to as inhibitors highlighted below.

\section{Inhibitors}

Health workers are vital to the global response to Universal Health coverage. With resources stretched to the limit and health systems under immense pressure, countries need more health workers on the ground to tackle the pandemic while continuing to provide other essential health services at all levels of the healthcare delivery system. The reason being that a stronger health workforce is key to the country's response to UHC and serves as the foundation of a resilient health system. Rather, the available limited healthcare workforce is being affected (ill health and death) by Covid-19, thus, it stands as an inhibitor to achieving UHC (Malelelo-Ndou, Ramathuba \& Netshisaulu 2019). Again, some countries are demonstrating that effective primary health care and a strong health workforce are among the most powerful ways to bring health services closer to communities, protect everyone from all health threats and inch closer to UHC. For fear of COVID-19 been transmitted even through the healthcare environment, members of the community avoid patronizing healthcare facilities at all levels, thus COVID19 stands as an inhibitor to UHC.

Furthermore, the UHC Partnership expands WHO's assistance and technical expertise to 115 countries, through funding from the European Union, the Grand Duchy of Luxembourg, Irish Aid, the French Ministry for Europe and Foreign Affairs, the Government of Japan, the United Kingdom - Foreign, Commonwealth and Development Office and Belgium. This global Partnership supports various states governments in strengthening health systems to accelerate progress towards UHC. Its work includes a special focus on health security and noncommunicable diseases. Rather than continuing in all these, attention is being drawn to tackling COVID-19 and its attendant consequences, which makes reaching the goal of achieving UHC looks untenable (Zhou, Yu, Du, et al 2020, Kempthorne et al, 2017).

In addition, Somalia's experience in addressing COVID-19 illustrates how investing in universal health coverage sets a strong foundation for health emergency preparedness and response. The Government is working assiduously to ensure that people can access quality health care without experiencing financial hardship. Now COVID-19 upsurge has brought a lot of hardship and financial lack (Zhou, Yu, Du, et al 2020). Once the healthcare system and people experience financial lack, it could reduce their demand for non-emergency or appointed care which shrinks the overall income. It means that a population`s financial lack can ultimately prevent patients from seeking inpatient treatments and elective services. At other times, healthcare workers in some facilities limit the number of cases to be attended by having a specified number of clients per day.

Another likely reason for COVID-19 being an inhibitor is- the widespread deaths related to COVID-19 has brought about significant variations in diagnosis of chronic disease in some European setting such as Netherlands (Dinmohamed et al 2020). Nationwide chronic disease Registry in the period between Feb 24, 2020, and April 12, 2020 - which are based on initial case ascertainment through pathological diseases notifications - indicate that there is a notable decrease in chronic illness diagnoses when compared with the pre-COVID-19 outbreak era (Dinmohamed et al 2020). 
In some instances, according to Dinmohamed et al (2020) account, to consult a general practitioner primarily, at the latent, non-specific chronic illness symptoms stage might have barriers sequel to wasting the general practitioner's time for non-COVID-19-related symptoms, assumptions about insufficient capacity for essential non-COVID-19-related health-care services, and anxiety about acquiring COVID-19 in a health-care setting. Moreover, most of the general practitioner consultations for non-acute issues are changed to telehealth to avoid contact with clients, meaning the impact of patient-healthcare worker one-on-one interaction is diminished. Below is a chart indicating the number of a chronic disease (cancer diagnoses) by week in Europe

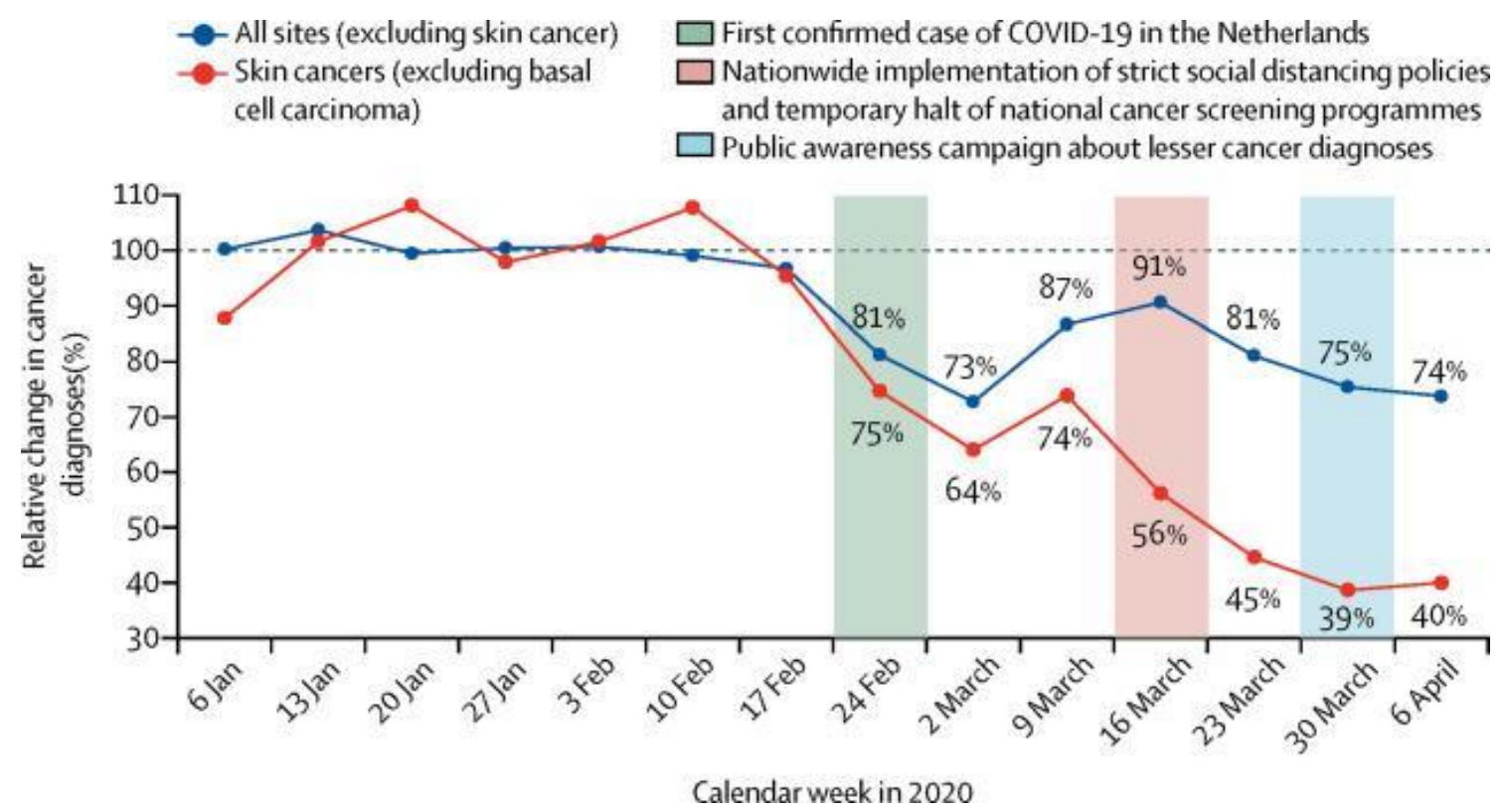

Figure 2: Number of cancer diagnoses by week in Europe (Netherlands) in the period between Jan 6, 2020 (calendar week 2) and April 12, 2020 (calendar week 15). Source: An excerpt from (Dinmohamed et al 2020)

Besides that, healthcare practitioners might postpone investigations for early symptoms that do not immediately hint towards a potentially serious diagnosis, resulting in delayed or postponed hospital referrals which could prompt health deterioration (Malelelo-Ndou, Ramathuba \& Netshisaulu 2019).

Moreover, hospitals might have postponed diagnostic evaluation or have longer turnaround times for diagnostic evaluation because many hospital-based resources are being allocated to tackle COVID-19. This could contribute to the overall delay experienced by patients from onset of chronic illness symptoms to diagnosis and treatment. Such delays are critical as infected individuals remain untreated in the community, providing more opportunities for transmission of the disease and adversely affecting the epidemic (Stephen, Pieter, John, Helden \& Brian 2008; Asch, Leake, Anderson, Gelberg 1998). Not least, national screening programmes for breast, colorectal, and cervical cancer are temporarily halted as of March 16, 2020, to alleviate the demand on the healthcare system due to COVID-19. The effect of this pause in cancer 
diagnosis might be more pronounced after extended periods of follow-up. However, this effect might be less notable for cervical cancer because screening aims to identify precancerous lesions. Collectively, fewer cancer diagnoses in the COVID-19 era will result from patient, doctor, and system factors.

Besides these, Bong et al (2020) state that the epidemic set back the management of all health care services, especially treatment and control of TB, HIV, and malaria, which are key aspects covered by Universal Health Coverage. The number of women giving birth in health centres in Sierra Leone dropped by $30 \%$; cesarean delivery rate dropped by $60 \%$. It is estimated that $\$ 2.2$ billion was lost from the gross domestic product of some countries as a result of COVID-19.

In addition, Bong et al (2020) found out that the global COVID-19 situation unfolds that countries are forced to take unprecedented drastic measures, including border closures, travel bans, and social distancing, we will likely witness the devastating and profound impact of this pandemic not only in health care but also on the world economy.

In extreme cases when patients are admitted to the hospital, the surge in critically ill patients may deprive surgical services of resources to the point of exclusion. Several regions have experienced this phenomenon and many are planning for this scenario, with the cancellation of all non-essential surgery for an initial period (Søreide et al 2020).

Not only that, operating theatres and anaesthesia machines may be converted to temporary respiratory support units for COVID-19 related ill patients. Postoperative recovery rooms and intermediate-care units may be converted as care units outside regular intensive care to manage sick patients with COVID-19. In this case, there is a real threat of disruption to all surgical services and difficulty maintaining even critical surgical care. In order to prepare, all nonessential elective surgery has been recommended to be cancelled in many healthcare systems and by surgical societies, but with variable suggestions and advice across regions and disciplines (Søreide et al 2020).

Reports from reproductive health stakeholders in a number of countries indicate large dropoffs in the number of women attending reproductive health clinics (Stopes, 2020). For example, the International planned parenthood federation (IPPF) - after conducting the largest survey thus far as to how sexual and reproductive health care has been affected by the pandemic - has reported the closure of 5,633 static and mobile clinics and community-based care outlets across 64 countries, or roughly 14 per cent of the total IPPF service delivery points in 2018 (Pratt, \& Frost, 2020).

\section{How can countries make progress towards UHC?}

Many countries are already making progress towards UHC amidst COVID-19. All countries can take action to move more rapidly towards it or to maintain the gains they have already made. In countries where health services have traditionally been accessible and affordable, governments are finding it increasingly difficult to respond to the ever-growing health needs of the populations and the increasing costs of health services.

Moving towards effective UHC requires strengthening health systems in all countries. Robust redirected efforts towards financing structures are key. When people have to pay most of the cost for health services out of their own pockets, the poor are often unable to obtain many of the services they need, and even the rich may be exposed to financial hardship in the event of 
severe or long-term COVID-19 illness. Thus, pooling funds from compulsory funding sources (such as mandatory insurance contributions) can spread the financial risks of illness across a population.

Improving health service coverage and health outcomes depends on the availability, accessibility, and capacity of health workers to deliver quality people-centred integrated care. Investments in quality primary health care practitioners (Public/Community Health Nurses) will be the cornerstone for achieving UHC around the world. Investing in the primary health care workforce is the most cost-effective way to ensure access to essential health care will improve. Good governance, sound systems of procurement and supply of medicines and health technologies and well-functioning health information systems are other critical elements to make progress towards the achievement of UHC.

\section{CONCLUSION}

In conclusion, COVID-19 has impacted negatively on mankind, including the likelihood of inhibiting a well-meaning UHC. However, world leadership can take a decisive step in increasing the healthcare workforce, increase funding and build human capacities to improve UHC in the face of COVID-19.

\section{REFERENCES}

Asch S, Leake B, Anderson R, Gelberg L (1998) Why do symptomatic patients delay obtaining care for tuberculosis? Am J Respir Crit Care Med 157: 1244-1248.

Bong, C. L., Brasher, C., Chikumba, E., McDougall, R., Mellin-Olsen, J., \& Enright, A. (2020). The COVID-19 pandemic: effects on low-and middle-income countries. Anaesthesia and analgesia.

Cuffari, B and Coveney, S. (2021) The Size of SARS-CoV-2 and its Implications. https://www.news-medical.net/health/The-Size-of-SARS-CoV-2-Compared-to-OtherThings.aspx.

Dinmohamed, A. G., Visser, O., Verhoeven, R. H., Louwman, M. W., van Nederveen, F. H., Willems, S. M., ... \& Siesling, S. (2020). Fewer cancer diagnoses during the COVID-19 epidemic in the Netherlands. The Lancet Oncology, 21(6), 750-751.

Enabulele O. 2020. Achieving Universal Health Coverage in Nigeria: Moving Beyond Annual Celebrations to Concrete Address of the Challenges. https://doi.org/10.1002/wmh3.328 Retrieved 6/02/2021.

Guo, YR., Cao, QD., Hong, ZS. et al. The origin, transmission and clinical therapies on coronavirus disease 2019 (COVID-19) outbreak - an update on the status. Military Med Res 7, 11 (2020). https://doi.org/10.1186/s40779-020-00240-0 Ihttps://covid19.who.int/table. Retrieved 5/02/2021.

Kempthorne P, Morriss WW, Mellin-Olsen J, Gore-Booth J. The WFSA Global Anesthesia Workforce Survey. Anesth Analg. 2017;125:981-990. [PubMed] [Google Scholar]

Malelelo-Ndou H, Ramathuba DU, Netshisaulu KG. Challenges experienced by health care professionals working in resource-poor intensive care settings in the Limpopo province of South Africa. Curationis. 2019;42: e1-e8. [PMC free article] [PubMed] [Google Scholar] 
New York Department of Health (2011) Foreign Countries with Universal Health Care. https://www.health.ny.gov/regulations/hcra/univ_hlth_care.htm. Retrieved $20^{\text {th }}$ February 2021

Pratt, B. A., \& Frost, L. (2020). COVID-19 and the status of women's, children's, and adolescents' health and rights: A targeted literature review of current evidence for action on universal health care (UHC) and accountability. UN SG's independent accountability panel for every woman, Every Child, Every Adolescent (IAP). Geneva: World Health Organization.

Søreide, K., Hallet, J., Matthews, J. B., Schnitzbauer, A. A., Line, P. D., Lai, P. B. S., ... \& Lorenzon, L. (2020). Immediate and long-term impact of the COVID-19 pandemic on delivery of surgical services. The British journal of surgery.

Stephen J. M, Pieter W. U, John H, van Helden and Brian G. W. (2008). The Effect of Diagnostic Delays on the Drop-Out Rate and the Total Delay to Diagnosis of Tuberculosis. PLOS ONE. Open Access Journal. https://doi.org/10.1371/journal.pone.0001933

Stopes M. Stories from the frontline: in the shadow of COVID-19. 2020. https://www.mariestopes.org/covid-19/stories-from-the-frontline/.

WHO (2012) Governments push for Universal Health Coverage as COVID-19 continues to devastate communities and economies. https://www.who.int/news-room/featurestories/detail/governments-push-for-universal-health. Retrieved 12/02/2021.

WHO (2019) Universal health coverage (UHC): Key facts. https://www.who.int/newsroom/fact-sheets/detail/universal-health-coverage-(uhc) Retrieved $20^{\text {th }}$ February 2021.

Zhou F, Yu T, Du R, et al. Clinical course and risk factors for mortality of adult inpatients with COVID-19 in Wuhan, China: a retrospective cohort study. Lancet. 2020; 395:1054-1062. [PMC free article] [PubMed] [Google Scholar]

WHO (2020) Recommendations to reduce risk of transmission of emerging pathogens from animals to humans in live animal markets or animal product markets. http://www.fao.org/2019-ncov/q-and-a/en/. Retrieved 12/02/2021.

WHO Health Emergency (2021). WHO Dashboard on Coronavirus disease (COVID-19) Homepage

World Health Organisation (WHO) 2020. Universal health coverage (UHC) www.who.int > Newsroom > Fact sheets > Detail. Retrieved 3/02/2021. 